\title{
Physicochemical Properties of Calcium Phosphate Based Coating on Gutta-Percha Root Canal Filling
}

\author{
Afaf Al-Haddad, Muralithran G. Kutty, \\ Noor Hayaty Abu Kasim, and Zeti Adura Che Ab Aziz \\ Department of Restorative Dentistry, Faculty of Dentistry, University of Malaya, 50603 Kuala Lumpur, Malaysia \\ Correspondence should be addressed to Afaf Al-Haddad; afaf_haddad3@yahoo.com and \\ Zeti Adura Che Ab Aziz; zetiaziz@um.edu.my
}

Received 16 February 2015; Revised 8 April 2015; Accepted 15 April 2015

Academic Editor: Angel Concheiro

Copyright (C) 2015 Afaf Al-Haddad et al. This is an open access article distributed under the Creative Commons Attribution License, which permits unrestricted use, distribution, and reproduction in any medium, provided the original work is properly cited.

\begin{abstract}
Dental Gutta-percha (GP) is a polymer based standard root canal filling material that has been widely used in dentistry. However, it has an inadequate sealing ability and adhesion to root dentin. The aim of this study is to coat GP with a bioactive material to enhance its sealing ability and adhesion to the root sealer and subsequently to the root dentin. The choice of coating method is limited by the nature of GP as it requires a technique that is not governed by high temperatures or uses organic solvents. In this study, biomimetic coating technique using 1.5 Tas-simulated body fluids (SBF) was employed to coat the treated GP cones. The coated samples were characterized using Fourier transform infrared spectroscopy (FTIR), X-ray Diffraction (XRD), and field emission scanning electron microscope (FESEM). The presence of hydroxyl, carbonate, and phosphate groups was detected by FTIR while the formation of hydroxyapatite (HA)/calcium phosphate was confirmed with XRD. FESEM revealed uniform, thin, and crystalline HA calcium phosphate coating. The adhesion of the coating to the GP substrate was assessed with microscratch technique. It was viable with cohesive failure mode. In conclusion, Tas-SBF is able to coat pretreated GP cones with a crystalline apatitic calcium phosphate layer.
\end{abstract}

\section{Introduction}

Gutta-percha (GP) is a natural polymer that undergoes manufacturing processing and incorporation of other fillers before application as root canal filling [1]. It is the gold standard root canal filling material and it has many advantages such as biocompatibility, nonstaining, and radiopacity [2]. However, it possesses an inadequate sealing ability and adhesion to root dentin [3]. The concept of coating the GP has been introduced to enhance the adhesion and sealing ability of root canal filling materials to the dentin and the sealer [4]. However, commercially available materials with coated GP with either methacrylate resin or glass ionomer-based materials were unable to hermetically seal the root canal and prevent leakage [5-7].

Coating of GP with a bioactive material that has similar components to the root dentin could enhance the bonding to the root sealers and subsequently to the root dentin. Hydroxyapatite (HA) or its precursor amorphous calcium phosphate is a bioactive material that could be produced in a uniform and a thin thickness. Theoretically, using these materials for root filling can lead to deposition of these inorganic particles at the root surface and increase the sealing ability and induce crystal growth on material surfaces [8]. Properties of GP including its low melting point [9] and its taper shape make its coating a challenge.

Synthetic or simulated body fluid (SBF) solutions are able to induce apatite calcium phosphate formation on metals, ceramics, or polymers immersed in them with proper surface treatments [10]. As reported by Kokubo et al., calcium phosphate is metastable in SBF and it eventually transforms into crystalline apatite. Once apatite nuclei are formed at initial stage, they will spontaneously grow by consuming the calcium and phosphate ions from the SBF to form a dense and uniform apatite layer [11]. Different SBF solutions have been used in literature to deposit $\mathrm{CaP}$ on substrates [12]. Tas-SBF solution was reported to have a $\mathrm{HCO}_{3}{ }^{-}$concentration mimicking the human plasma $(27 \mathrm{mM})$ and it was able to produce even carbonated calcium phosphate coating compared to conventional SBF and revised SBF [10]. 
TABLE 1: Components of 1.5x Tas-SBF [10].

\begin{tabular}{lcc}
\hline Order & Reagents & Weight g/L \\
\hline 1 & $\mathrm{NaCl}$ & 9.8184 \\
2 & $\mathrm{NaHCO}_{3}$ & 3.4023 \\
3 & $\mathrm{KCl}$ & 0.5591 \\
4 & $\mathrm{Na}_{2} \mathrm{HPO}_{4} \cdot 2 \mathrm{H}_{2} \mathrm{O}$ & 0.2129 \\
5 & $\mathrm{MgCl}_{2} \cdot 6 \mathrm{H} 2 \mathrm{O}$ & 0.4574 \\
6 & $1 \mathrm{M} \mathrm{HCl}_{2}$ & $15 \mathrm{~mL}$ \\
7 & $\mathrm{CaCl}_{2} \cdot 2 \mathrm{H}_{2} \mathrm{O}$ & 0.5513 \\
8 & $\mathrm{Na}_{2} \mathrm{SO}_{4}$ & 0.1065 \\
9 & $\left(\mathrm{CH}_{2} \mathrm{OH}_{3} \mathrm{CNH}_{2}\right.$ & 9.0855 \\
10 & $1 \mathrm{M} \mathrm{HCl}$ & $50 \mathrm{~mL}$ \\
\hline
\end{tabular}

In addition, it can induce a nanoporous apatitic calcium phosphate formation on metal and bone substitutes under the biomimetic conditions of $37^{\circ} \mathrm{C}$ and $\mathrm{pH} 7.4[10,13]$. However, the in vitro apatite-inducing ability of Tas-SBF on a polymer substrate has not yet been reported. The aim of this study is to coat the pretreated GP cones with uniform thickness of apatite calcium phosphate layer using the Tas-SBF solution.

\section{Experimental Procedures}

2.1. Preparation and Characterization of Coating. The coating technique was performed according to previously published study [10] as follows. Size 40 and 0.06 taper GP cones (Iso coded Dentsply, Maillefer, USA) were used as substrate. The cones were first abraded with a \#1000 SiC paper (FEPA P\#1000, Struers) and subsequently washed with acetone, ethanol, and deionized water in an ultrasonic bath (WiseClean, Korea). Each one of the GP cones was then immersed vertically by using stainless steel wires in $50 \mathrm{~mL}$ of a $5 \mathrm{M}$ $\mathrm{NaOH}$ (EMSURE, Germany) solution at $60^{\circ} \mathrm{C}$ for 24 hours in a glass bottle, followed by washing with deionized water and drying at $40^{\circ} \mathrm{C} .1 .5$ TRIS-buffered, $27 \mathrm{mM}$ simulated body fluid solutions (1.5x Tas-SBF) were freshly prepared by adding the reagents in order and quantity as given in Table 1 . The $\mathrm{NaOH}$ treated GP cones were soaked at $37^{\circ} \mathrm{C}$ in $50 \mathrm{~mL}$ of $1.5 \mathrm{x}$ Tas-SBF of pH 7.4 in tightly sealed Scott (Scott, USA) media bottles of $100 \mathrm{~mL}$ capacity, for a period of 10 days. SBF solution was changed every 48 hours. GP cones were removed from the SBF solution at the end of respective soaking times and washed with deionized water, followed by drying at $37^{\circ} \mathrm{C}$. The coating on GP cones was analyzed using an X-ray diffractometer (XRD; PANalytical-EMPYREAN), operated at $45 \mathrm{kV}$ and $40 \mathrm{~mA}$ with monochromated $\mathrm{Cu} \mathrm{K} \alpha$ radiation. The XRD data were collected at $2 \theta$ values from $10^{\circ}$ to $70^{\circ}$ at a rate of $0.01^{\circ}$ per minute. Fourier-transform infrared (FTIR, Nicolet 6700, Thermo-Nicolet) analyses were performed directly on the coated GP cones. Surface morphology of the coated GP was evaluated with a field emission scanning electron microscope (Low Vaccum Operating Mode, Quanta FEG 250, Holland) at different magnification.

2.2. Microscratch Adhesion Test. The coatings were subjected to a series of adhesion strength measurements using a Micro

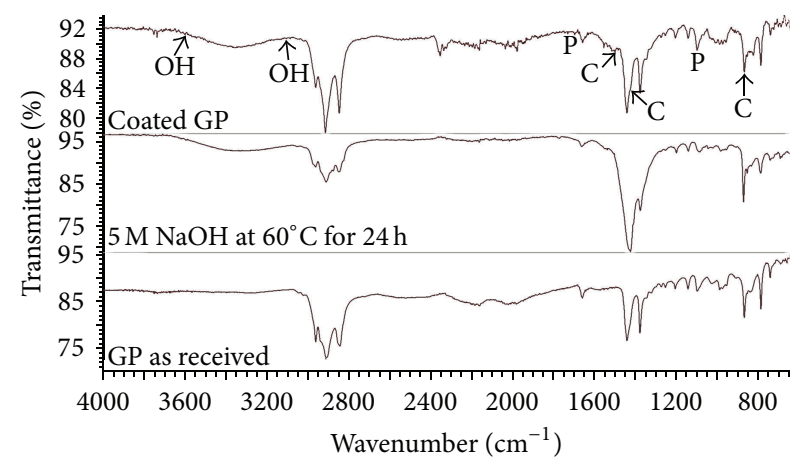

FIGURE 1: FTIR analysis of GP, GP treated with $\mathrm{NaOH}$ for $24 \mathrm{~h}$, and Tas-SBF coated GP; OH: hydroxyl, C: $\mathrm{CO}_{3}{ }^{-2}$, and $\mathrm{P}: \mathrm{PO}_{4}{ }^{-3}$.

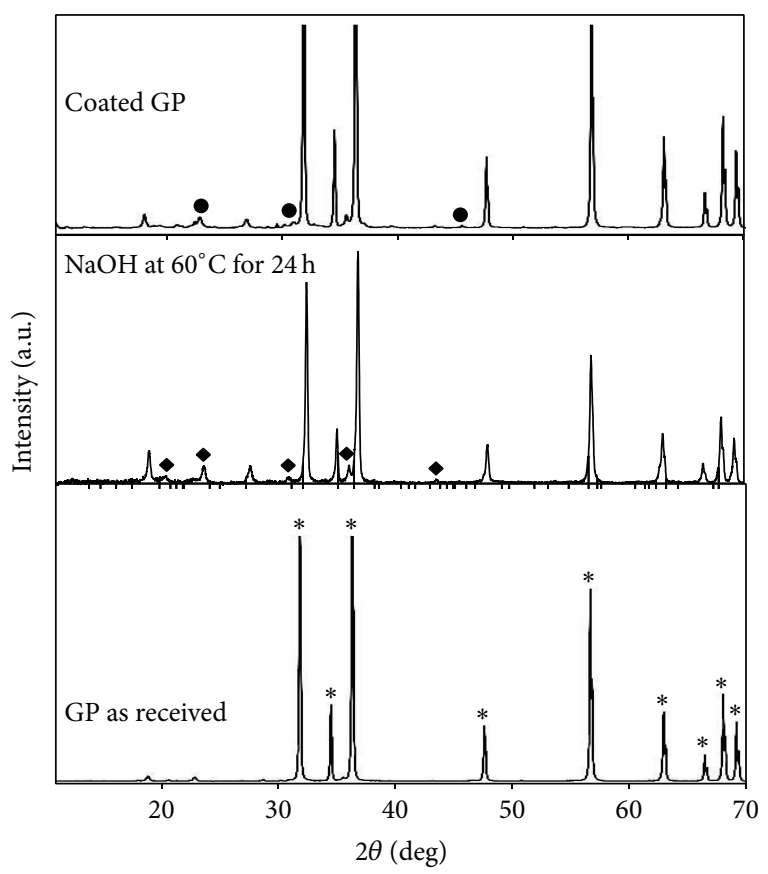

FIGURE 2: XRD analysis of GP, GP treated with $\mathrm{NaOH}$, and Tas-SBF coated GP. ${ }^{*} \mathrm{ZnO}(\mathrm{GP}){ }^{\bullet} \mathrm{NaOH}{ }^{\bullet} \mathrm{HA} /$ calcium phosphate.

Materials NanoTest (Wrexam, UK) microscratch testing platform. A conical spherical Rockwell diamond stylus of $25 \mu \mathrm{m}$ radius was used. Three cones were subjected to the test and two scratches were made on the coating of each cone with scratching progressive load from 0 to $1000 \mathrm{mN}$. The different scratch loads correspond to loading rates of 1.0 and $2.5 \mathrm{mN} / \mathrm{s}$. Topography scanning and scratching was done using a scan speed of $2 \mu \mathrm{m} / \mathrm{s}$. The scratching length was fixed to $2500 \mu \mathrm{m}$. The scratch direction was from right side (coronal) to left side (apical). The critical load (peeling-off load) was recorded based on the scratch profile of the load-displacement graph. It was verified with an optical image of the scratch path since it was discovered that some failure modes can occur without a noticeable change in the scratch profile. The images of the scratch paths were taken using an Olympus BX51 optical microscope (Olympus BX-UCB, Japan) with $\times 50$ 


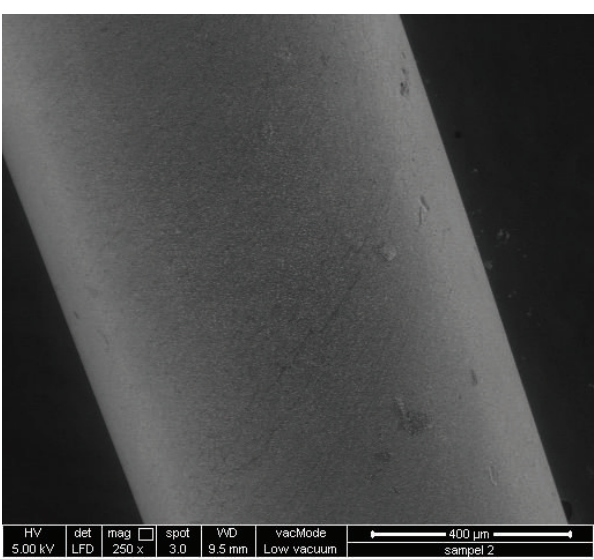

(a)

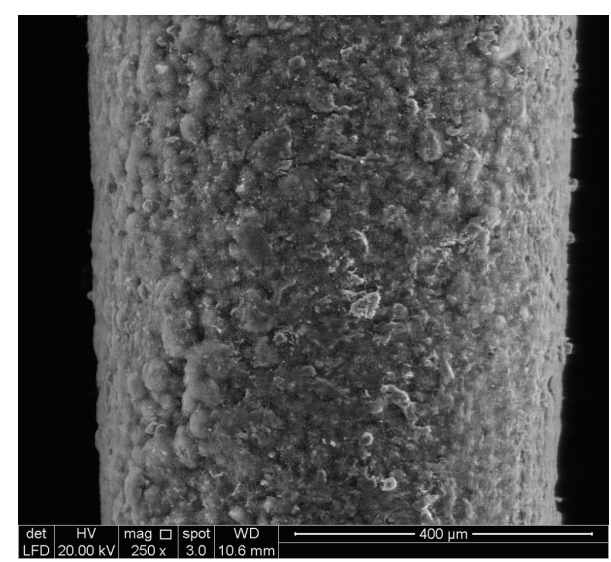

(b)

FIGURE 3: SEM morphological surface of (a) uncoated GP cone and (b) coated GP cone.

magnification. The critical load, the load at which the coatings are delaminated along the scratch path, was recorded.

\section{Results}

3.1. Characterization of the Coating. Figure 1 shows the FTIR spectrum for the GP (as received), $\mathrm{NaOH}$ treated GP, and SBF coated GP. The $\mathrm{NaOH}$ treated sample clearly indicates the presence of the $\mathrm{OH}$ group which is formed on the surface of the GP after treatment with $5 \mathrm{M} \mathrm{NaOH}$ at $60^{\circ} \mathrm{C}$ for $24 \mathrm{~h}$. After immersion in the SBF solution for 10 days, FTIR showed coating consisting of carbonated $\left(\mathrm{CO}_{3}{ }^{-2}\right.$ ion absorption bands seen at $1470-1420$ and $875 \mathrm{~cm}^{-1}$ ) calcium phosphates. The presence of the stretching and the vibrational modes of the $\mathrm{OH}$ group at 3100 and $3571 \mathrm{~cm}^{-1}$ indicated that hydroxyapatite was also formed in the coating.

Figure 2 shows the XRD patterns for the GP, $\mathrm{NaOH}$ treated GP, and Tas-SBF coated GP. NaOH treated samples showed the presence of $\mathrm{NaOH}$ peaks confirming the existence of $-\mathrm{OH}$ bond on the surface. Tas-SBF coated sample indicated the formation of apatite/calcium phosphate [JCPDS card090432].

SEM (Figure 3) shows formation of a uniform layer of coating on the GP. The morphology of the coating at different magnification is shown in Figure 4. Figure 4(c) shows the crystalline form of apatite/calcium phosphate. The SEM measurements of the coating thickness gave a uniform coating with a thickness range of $14-19 \mu \mathrm{m}$ and an average of $16 \mu \mathrm{m}$.

3.2. Microscratch Adhesion. According to the two different loading rates 0.1 and $2.5 \mathrm{mN} / \mathrm{s}$, the mean critical load was $535.99 \mathrm{mN}$ and $1001.46 \mathrm{mN}$, respectively. Figure 5 shows an example of a scratch profile of $\mathrm{CaP}$ coatings along with a typical microscratch result. The failure mode (Figure 6) was started as Arc Tensile Cracks according the Atlas of failure mode of scratch test [C1624-05; 2010]. This failure described as semicircular microcracks formed behind the stylus.
This type of failure mode is cohesive failure. The total failure was recovery spallation mode.

\section{Discussion}

SBF solutions of physiological pH 7.4 and temperature $37^{\circ} \mathrm{C}$ have been used in experimental studies for coating metals, polymers, and ceramics with a thin layer of carbonated apatite $\mathrm{CaP}[10,13]$. There are two essential steps for coating: first, pretreatment of substrate surface to deposit the hydroxyl-OH that is essential for initiating the aggregation of precipitate [12]; second, changing or replenishing the solution as with the advance of precipitate formation the level of $\mathrm{pH}$ increased and the level of CaP precipitate decreased [14].

In the current study, we were able to produce a uniform coating of apatite/calcium phosphate with no cracks observed. This is an improvement from the previously reported study where cracks were present due to hydration [10]. This positive result can be attributed to the thin coatings achieved in this study. With thinner coatings, the hydration occurs in a more uniform manner throughout the thickness of the coating.

This study was also able to confirm the presence of $-\mathrm{OH}$ in the coating with FTIR and XRD analysis. Presence of -OH group is an indicator to formation of hydroxyapatite. This is contrary to previous reported studies that were not able to confirm the presence of the $-\mathrm{OH}$ group [8]. We believe this finding to be due to the modification made by replacing the Tas-SBF solution rather than replenishment done by previous researchers [10]. This can also be due to the polymeric nature of the substrate used.

In this study, we used the scratch test method to evaluate the adhesion between the GP and the coating. Although pullout tensile test is the most predominant way to measure the adhesion of coating, it is affected by different factors such as surface roughness $[15,16]$. Whereas scratch results only characterize the interface adhesion, therefore it could a more suitable method to evaluate the delamination possibility of 


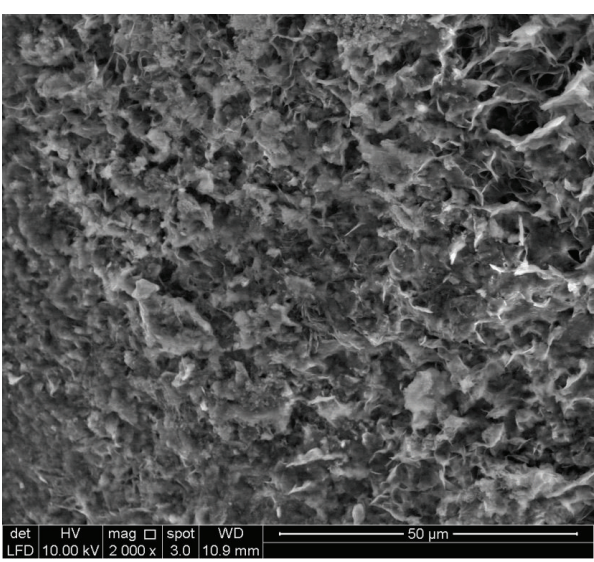

(a)

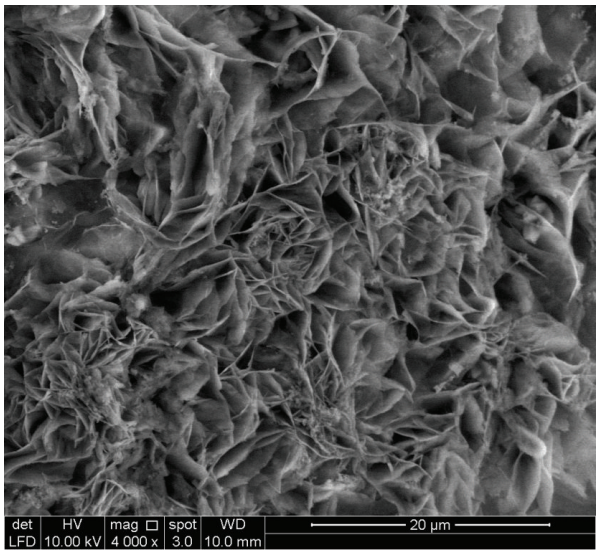

(c)

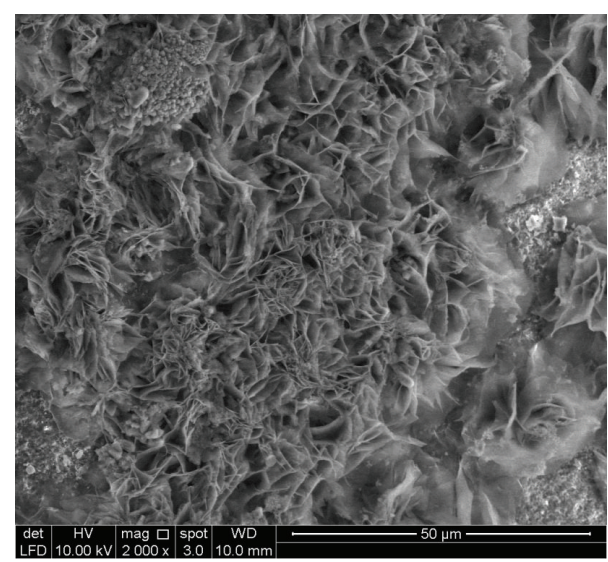

(b)

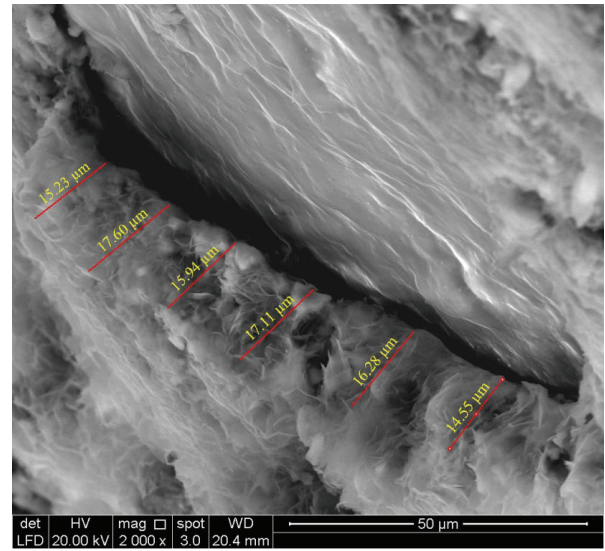

(d)

FIGURE 4: SEM morphological surface of coated GP with different magnifications (a), (b), and (c). (d) shows the coating thickness.

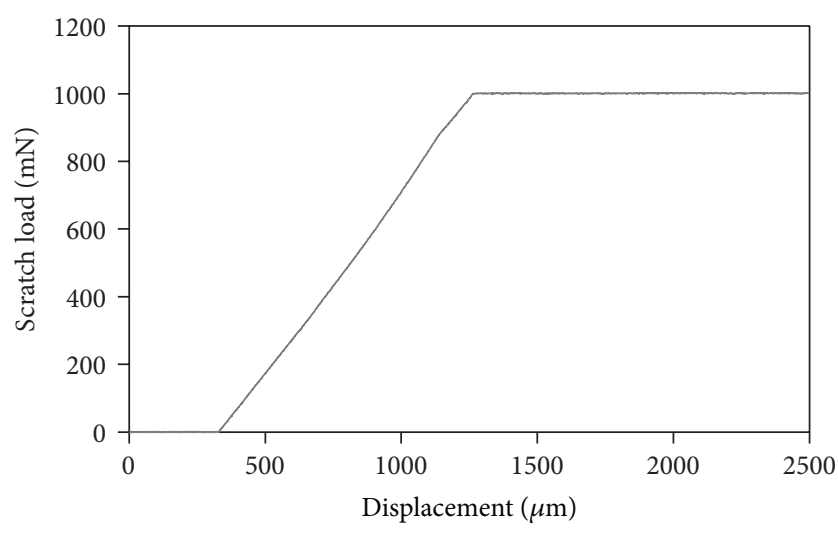

(a)

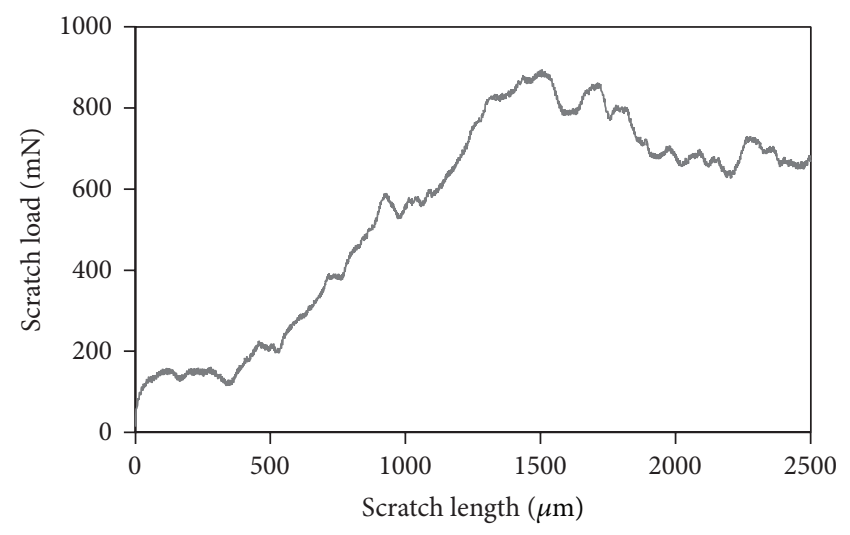

(b)

FIGURE 5: (a) Microscratch loading profile; (b) typical microscratch result.

the coatings [16]. Furthermore, the taper shape of the GP cone makes it inappropriate for pull-out tensile testing.

Due to lack of standard value to evaluate the adhesion test, we compared the adhesion value obtained in this study to a previous study that reported a good adhesion $(390 \mathrm{mN})$ of pure $\mathrm{HA}$ coating on $\mathrm{Ti}_{6} \mathrm{Al}_{4} \mathrm{~V}$ substrate [16]. In the current study, the good adhesion strength and presence of cohesive failure mode are attributed to the existence of both mechanical interlocking and chemical bonding between coating and substrate. During pretreatment of GP with $\mathrm{NaOH}$, hydroxyl group can react chemically and bond with the hydrophobic polyisoprene components of GP [4]. Moreover, the rough 

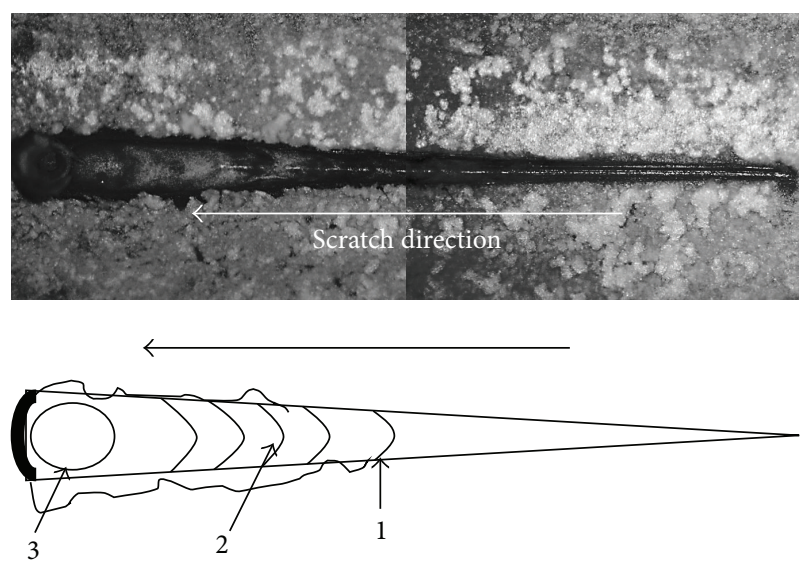

FIgUre 6: Failure mode of CaP/HA coated GP. (1) Arch tensile cracking, (2) delamination, and (3) total failure (recovery spallation).

morphological structure of GP due to presence of zinc oxide in polymeric matrix as well as the small size of $\mathrm{CaP}$ precipitates is believed to enhance the mechanical interlocking bond.

Coating of the GP with apatite/calcium phosphate is proposed to enhance its surface properties as root canal filling material. Similarity of the coating components to hydroxyapatite in root dentin might increase the chemical adhesion of some sealers that bond chemically to root dentin such as glass ionomer-based sealer [17]. Furthermore, the roughness of coating surface could permit penetration and mechanical interlocking of root sealer particles into the coated GP surface.

\section{Conclusions}

With the limitation of this study, the biomimetic technique using Tas-SBF is able to evenly coat pretreated GP cones with a crystalline apatitic calcium phosphate layer.

\section{Conflict of Interests}

The authors declare that they have no conflict of interests.

\section{Acknowledgment}

This study was supported by the UMRG Grant (no. RG407/12HTM), University of Malaya, Malaysia.

\section{References}

[1] M. Tanomaru-Filho, R. Bosso, C. A. S. Bier, and J. M. GuerreiroTanomaru, "Thermoplasticity of microseal and TC gutta-percha (Tanaka de Castro) and three gutta-percha cones," Brazilian Journal of Oral Sciences, vol. 8, no. 2, pp. 81-83, 2009.

[2] C. H. J. Hauman and R. M. Love, "Biocompatibility of dental materials used in contemporary endodontic therapy: a review. Part 2. Root-canal-filling materials," International Endodontic Journal, vol. 36, no. 3, pp. 147-160, 2003.

[3] G. Shipper, D. Ørstavik, F. B. Teixeira, and M. Trope, "An evaluation of microbial leakage in roots filled with a thermoplastic synthetic polymer-based root canal filling material (Resilon)," Journal of Endodontics, vol. 30, no. 5, pp. 342-347, 2004.

[4] E. Haschke, "Methods of filling a root canal with adhesive endodontic cones and polymerizable filling and sealing materials," Google Patents, 2007.

[5] S. Bouillaguet, B. Bertossa, I. Krejci, J. C. Wataha, F. R. Tay, and D. H. Pashley, "Alternative adhesive strategies to optimize bonding to radicular dentin," Journal of Endodontics, vol. 33, no. 10, pp. 1227-1230, 2007.

[6] F. Monticelli, J. Sword, R. L. Martin et al., "Sealing properties of two contemporary single-cone obturation systems," International Endodontic Journal, vol. 40, no. 5, pp. 374-385, 2007.

[7] C. Carvalho, J. Martinelli, J. Bauer et al., "Micropush-out dentine bond strength of a new gutta-percha and niobium phosphate glass composite," International Endodontic Journal, vol. 48, no. 5, pp. 451-459, 2015.

[8] J. I. Johns, J. N. R. O’Donnell, and D. Skrtic, "Selected physicochemical properties of the experimental endodontic sealer," Journal of Materials Science: Materials in Medicine, vol. 21, no. 2, pp. 797-805, 2010.

[9] M. R. Miner, D. W. Berzins, and J. K. Bahcall, "A comparison of thermal properties between gutta-percha and a synthetic polymer based root canal filling material (Resilon)," Journal of Endodontics, vol. 32, no. 7, pp. 683-686, 2006.

[10] S. Jalota, S. B. Bhaduri, and A. C. Tas, "Effect of carbonate content and buffer type on calcium phosphate formation in SBF solutions," Journal of Materials Science: Materials in Medicine, vol. 17, no. 8, pp. 697-707, 2006.

[11] T. Kokubo, H.-M. Kim, M. Kawashita, and T. Nakamura, "Bioactive metals: preparation and properties," Journal of Materials Science: Materials in Medicine, vol. 15, no. 2, pp. 99-107, 2004.

[12] T. Kokubo and H. Takadama, "How useful is SBF in predicting in vivo bone bioactivity?" Biomaterials, vol. 27, no. 15, pp. 29072915, 2006.

[13] S. Jalota, S. B. Bhaduri, and A. C. Tas, "Using a synthetic body fluid (SBF) solution of $27 \mathrm{mM} \mathrm{HCO}_{3}^{-}$to make bone substitutes more osteointegrative," Materials Science and Engineering $C$, vol. 28, no. 1, pp. 129-140, 2008.

[14] P. A. Marques, M. C. F. Magalhães, and R. N. Correia, "Inorganic plasma with physiological $\mathrm{CO}_{2} / \mathrm{HCO}_{3}^{-}$buffer," Biomaterials, vol. 24, no. 9, pp. 1541-1548, 2003.

[15] Y.-Y. Wang, C.-J. Li, and A. Ohmori, "Influence of substrate roughness on the bonding mechanisms of high velocity oxy-fuel sprayed coatings," Thin Solid Films, vol. 485, no. 1-2, pp. 141-147, 2005.

[16] K. Cheng, C. Ren, W. Weng et al., "Bonding strength of fluoridated hydroxyapatite coatings: a comparative study on pull-out and scratch analysis," Thin Solid Films, vol. 517, no. 17, pp. 5361-5364, 2009.

[17] R. Weiger, T. Heuchert, R. Hahn, and C. Löst, "Adhesion of a glass ionomer cement to human radicular dentine," Dental Traumatology, vol. 11, no. 5, pp. 214-219, 1995. 

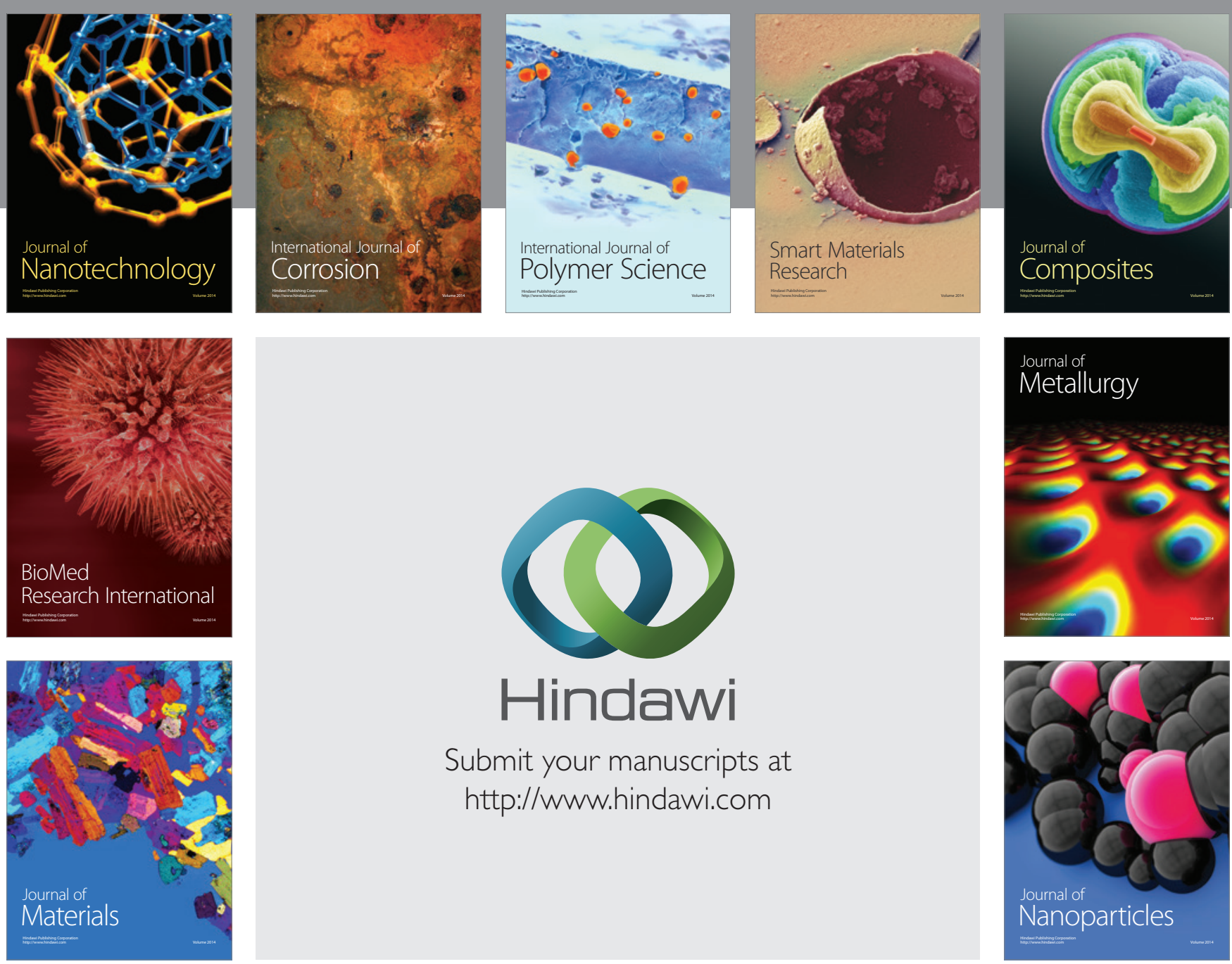

Submit your manuscripts at http://www.hindawi.com
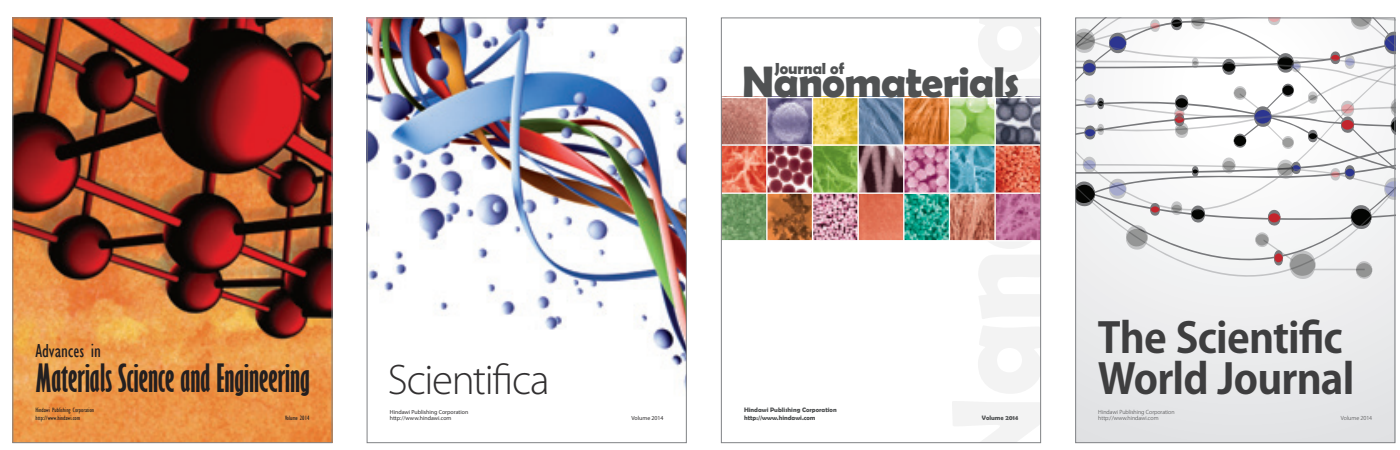

\section{The Scientific World Journal}
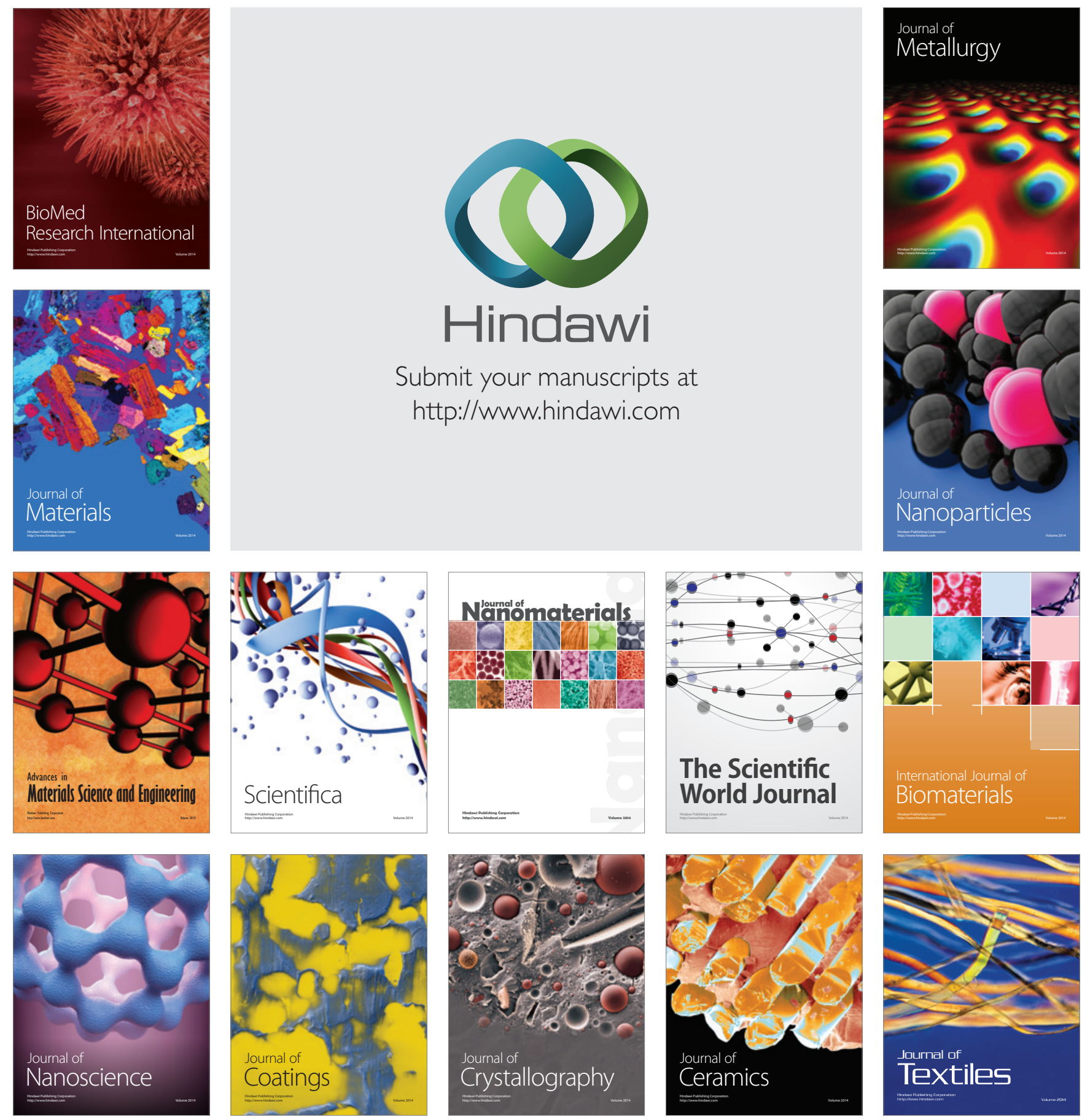